\title{
SETAC Europe Young Scientist LCA Award 2017 for Eléonore Loiseau
}

\author{
Joost Dewaele $^{1}$ (i) $\cdot$ on behalf of the SETAC Europe LCA steering committee
}

Received: 26 April 2017 / Accepted: 17 May 2017 / Published online: 2 June 2017

(C) Springer-Verlag Berlin Heidelberg 2017

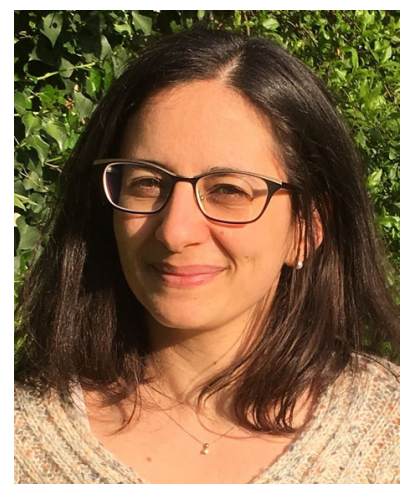

At the 27th SETAC Europe annual meeting, 7-11 May 2017, Brussels (Belgium), Eléonore Loiseau received the SETAC Europe Young Scientist LCA Award 2017.

Eléonore is an agro-engineer by formation (AgroParisTech), and finished her $\mathrm{PhD}$ in 2014 at Montpellier SupAgro, France. Her main research focused on the development of methodological proposals for performing an environmental assessment of territories as a whole based on the LCA framework, with an implementation in the French Mediterranean case study of Bassin de Thau. The term 'territorial' LCA is

Joost Dewaele

dewaele.j@pg.com

1 Procter and Gamble, Grimbergen, Belgium now emerging as a new LCA-based application as illustrated by a recent track in the latest Montpellier SETAC LCA case study conference.

Her contributions to broadening the LCA scope to a territory (including all production and consumption activities), hereby enabling quantitative LCA-based decision support for land planning, is highly valued. Without a doubt, this pioneering work is highly relevant for industry, government, and academia, and has served the larger LCA community via meaningful developments in LCA methodology and application thereof.

Eléonore is well known for her ability to work in a complex multi-disciplinary context, and to bridge gaps between environmental impact assessment and unexplored application fields in LCA. This is demonstrated by her supervision in two $\mathrm{PhD}$ projects, one with focus on the integration of economic modeling in territorial LCA, and another that investigates the effects of habitat fragmentation on biodiversity in LCIA. Finally, and further supporting the inter-disciplinary background of Eléonore, she has demonstrated her skills through recent involvement within the PEER European partnership research network for evaluating quantitative assessment tools toward a green economy.

Eléonore is the well-deserved winner of the 2017 SETAC Europe Young Scientist LCA Award. With this, we congratulate Eléonore with the award, with the work already accomplished, and wish her a fruitful continuation of her activities in her position at IRSTEA (French National Research Institute of Science and Technology for Environment and Agriculture) within the dynamic ELSA research group. 